irradiation, the samples were placed in the dark because biacetyl absorbs visible light and may undergo photochemical reaction. The concentrations of the styrylamines were $3.5 \mathrm{mmol} / \mathrm{dm}^{3}$ (1a) and $1.5 \mathrm{mmol} / \mathrm{dm}^{3}$ (1b) and those of biacetyl were 5-20 $\mathrm{mmol} / \mathrm{dm}^{3}$. The consumption of biacetyl during irradiation was negligible.

Stern-Volmer Plot for the Fluorescence of la or $1 \mathrm{~b}$. The samples were purged with argon. The extinction coefficients of the styrylamines and biacetyl at the excitation wavelength (254 $\mathrm{nm}$ ) are as follows: $1 \mathrm{a}, \epsilon_{254}=5600 ; 1 \mathrm{~b}, \epsilon_{254}=12600$; biacetyl, $\epsilon_{254}$ $=14$.

Quantum Yield Determination. Hexanone actinometry was used. Irradiation was performed with the Rayonet photochemical reactor. The samples in quartz tubes were purged with argon. After irradiation the degree of reaction was determined by the NMR spectroscopy.

Acknowledgment. This work was supported by a Grant-in-Aid for Scientific Research (No. 02640379) from the Ministry of Education, Science and Culture of Japan.

Supplementary Material Available: ${ }^{1} \mathrm{H}$ NMR spectra of $1 \mathrm{~g}$ and $2 \mathrm{c}$ ( 2 pages). This material is contained in many libraries on microfiche, immediately follows this article in the microfilm version of the journal, and can be ordered from the ACS; see any current masthead page for ordering information.

\title{
Correlation of Solvolytic Reactivities of 1,1,1-Trifluoro-2-phenyl-2-propyl, 1-tert-Butyl-1-phenylmethyl, and Some Related Tosylates ${ }^{\dagger}$
}

\author{
Kwang-Ting Liu,* Jye-Shane Yang, Shu-Mei Chang, Yan-Shyi Lin, Hun-Chang Sheu, and \\ Meng-Lin Tsao \\ Department of Chemistry, National Taiwan University, Taipei, Taiwan 107, Republic of China
}

Received August 29, 1991

\begin{abstract}
Solvolysis of 1,1,1-trifluoro-2-phenyl-2-propyl tosylate (3), 2,2,2-trifluoro-1-(4'-methylphenyl)ethyl tosylate (4), 1-tert-butyl-1-phenylmethyl tosylate (5), 1-tert-butyl-1-(3'-chlorophenyl)methyl tosylate (6), and 1-(3',5'dichlorophenyl)-2,2,2-trifluoro-1-phenylethyl tosylate (7) in a variety of solvents were found to give $\log k-Y_{\text {OT }}$ plots with significant deviations from linearity $(R=0.95-0.98)$. The data points for those measured in aqueous acetone always showed depression from the line, whereas those measured in nonnucleophilic solvents were on the line. On the other hand, 3, 4, 6, and 7 all showed excellent linear relationships $(R>0.99)$ for $\log k$ against $\log k(5)$. Additional evidence for the limiting $S_{N} 1$ mechanism in the solvolysis of 5 was given. Similar to the previous work (refs 11-13) a new $Y_{\mathrm{BnOT}}$ scale based on the solvolysis rates of 5 for correlating the solvolytic reactivity of benzylic tosylates involving charge delocalizations to the aryl moiety in the cationic transition states was then proposed. The advantages of using this new $Y$ scale of solvent ionizing powers were discussed. The importance of solvent nucleophilicities in the solvolysis of primary benzylic tosylate 8 and unhindered deactivating secondary benzylic tosylates 9 and 10 was confirmed.
\end{abstract}

In 1948 the Grunwald-Winstein equation (1) was stated to define the first scale of empirical solvent ionizing power (Y) based on the solvolytic rate constants of tert-butyl chloride. ${ }^{1}$ Multiparameter equations, such as (2), ${ }^{2}$ were

$$
\begin{gathered}
\log \left(k / k_{\mathrm{o}}\right)=m Y \\
\log \left(k / k_{\mathrm{o}}\right)=m Y+l N
\end{gathered}
$$

then introduced to accommodate the effect of the solvent nucleophilicity. Later studies indicated the use of 1- or 2-adamantyl tosylate as a better reference for defining the solvent ionizing power. ${ }^{3,4}$ Moreover, the necessity of using different $Y_{X}$ scales to correlate the solvolytic reactivity of substrates containing different leaving groups $(X)$ was first shown by Bentley and co-workers. ${ }^{5} A$ variety of $Y_{X}$ scales based on 1- or 2-substituted adamantanes have thus been developed ${ }^{6}$ and have been generally considered as an important set of solvent parameters for the understanding of the correlation of solvolytic reactivities. ${ }^{7}$ The observation of dispersed $\log k-Y_{\mathrm{X}}$ plots due to the rate constants measured in nonnucleophilic solvents, such as those that have been noted in the cases of tert-butyl halides ${ }^{5,8}$ and 2-(trifluoromethyl)-2-propyl triflate, ${ }^{9}$ has been considered as an useful probe for detecting nucleophilic solvent assistance. ${ }^{10}$

${ }^{\dagger}$ Dedicated to Professor Herbert C. Brown on the occasion of his 80th birthday.
On the other hand, we recently demonstrated the advantage of using a new $Y_{\mathrm{BnCl}}$ scale based on 2-aryl-2chloroadamantane $1 \mathbf{a}^{11}$ over the $Y_{\mathrm{Cl}}$ based on 1-chloroadamantane $(2)^{5}$ to describe the solvent ionizing power of a large number of solvents for correlating the solvolytic reactivity of tertiary benzylic chlorides by eq 1 . A similar approach has also been found to be successful for benzylic bromides ${ }^{12}$ and $p$-nitrobenzoates ${ }^{13}$ by employing the corresponding 2-aryl-2-adamantyl derivatives $1 \mathrm{~b}$ and $1 \mathrm{c}$, re-

(1) Grunwald, E.; Winstein, S. J. Am. Chem. Soc. 1948, 70, 846.

(2) Winstein, S.; Grunwald, E.; Jones, H. W. Ibid. 1951, 73, 2700.

(3) Fry, J. L.; Lancelot, C. J.; Lam, L. K. M.; Harris, J. M.; Raber, D. J.; Hall, R. E.; Schleyer, P. v. R. Ibid. 1970, 2538.

(4) Kevill, D. N.; Kolwyck, K. C.; Weitl, F. L. Ibid. 1970, 7300

(5) Bentley, T. W.; Carter, G. E. J. Am. Chem. Soc. 1982, 104, 5741.

(6) Bentley, T. W.; Llewellyn, G. Progr. Phys. Org. Chem 1990, 17, 121.

(7) For examples of some popular advanced textbooks: (a) Lowry, $T$. H.; Richardson, K. S. Mechanism and Theory in Organic Chemistry, 3rd ed.; Harper \& Row: New York, 1987; pp 335-340. (b) Ritchie, C. D. Physical Organic Chemistry; Maecel Dekker: New York and Basel, 1990; pp 66-69.

(8) Bentley, T. W.; Brown, C. T.; Parker, W.; Watt, C. I. F. J. Am. Chem. Soc. 1979, 101, 2486.

(9) Jansen, M. P.; Koshy, K. M.; Mangru, N. N.; Tidwell, T. T. Ibid. $1981,103,3863$

(10) Bentley, T. W.; Roberts, K. J. Chem. Soc., Perkin Trans. 2 1989, 1055.

(11) (a) Liu, K.-T.; Sheu, H.-C.; Chiu, P.-F.; Hu, C.-R. Tetrahedron Lett. 1990, 25, 3611. (b) Liu, K.-T.; Sheu, H.-C. J. Org. Chem. 1991, 56, 3021.

(12) Liu, K.-T.; Sheu, H.-C. J. Chin. Chem. Soc. (Taipei) 1991, $38,29$. 463.

(13) Liu, K.-T.; Chen, H.-I.; Chin., C.-P. J. Phys. Org. Chem. 1991, 4 ,

1992 American Chemical Society 
spectively, as the reference substrates.<smiles>[X]C1([Al])C2CC3CC(C2)CC1C3</smiles>

1

1a $\mathrm{Ar}=3^{3} \mathrm{CCC}_{8} \mathrm{H}_{4}, \mathrm{X}=\mathrm{Cl}$

1b $\mathrm{Ar}=4^{\prime}-\mathrm{CF}_{3} \mathrm{C}_{8} \mathrm{H}_{4}, \mathrm{X}=\mathrm{Br}$

1c $A r=C_{8} H_{5}, X=$ OPNB

1d $\mathrm{Ar}=$ 4 $^{-}-\mathrm{CF}_{3} \mathrm{C}_{8} \mathrm{H}_{4}, \mathrm{X}=\mathrm{OTs}$

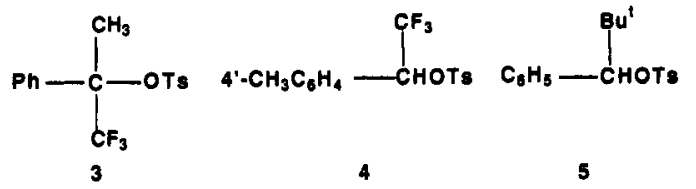

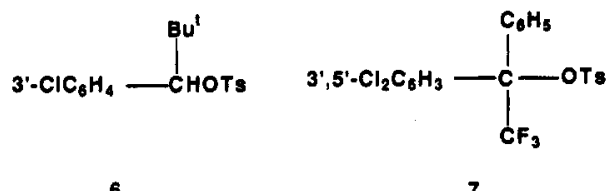

Tosylates are among the most commonly employed substrates in solvolytic studies. The solvolysis of $1,1,1$ trifluoro-2-phenyl-2-propyl tosylate (3) was considered to be a limiting $S_{N} 1$ process from the linear $\log k-Y_{\mathrm{OT}}$ relationship realized in alcoholic and acidic solvents and from other kinetic evidence. 14,15 The same conclusion was also reached in the case of 2,2,2-trifluoro-1-(4'-methylphenyl)ethyl tosylate (4). ${ }^{16}$ Extended study on the solvolytic behavior of tosylates 3 and 4 in additional solvents is thus desirable to examine the applicability of $Y_{\mathrm{OTs}}$ or the necessity of developing a new $Y_{\mathrm{BnX}}$ scale in correlating $\log k s$ for benzylic tosylates.

Preliminary study on the solvolysis of 3 in aqueous acetone revealed deviations from the original linear $\log k$ - Y ${ }_{\text {OT }}$ plot. ${ }^{17}$ The tertiary 2-aryl-2-adamantyl tosylate 1d would be expected to be unstable and too reactive to define a " $Y_{\mathrm{BnOTz}}$ " scale for benzylic tosylates from accurate kinetic measurements. Other tosylates will thus used. The solvolysis of 1-aryl-1-tert-butylmethyl tosylates has been shown to proceed with $k_{c}$ mechanism without nucleophilic solvent assistance or methyl participation. ${ }^{18,19}$ We now wish to report the results of our independent studies on the solvolysis of 1-tert-butyl-1-phenylmethyl tosylate (5) and some other representative tosylates. The $Y_{\mathrm{OTs}}$ scale was found to be not an appropriate one for the correlation of reactivities. A new $Y_{\mathrm{BnOTs}}$ scale ${ }^{17 \mathrm{~b}}$ is proposed, and its advantages over $Y_{\mathrm{OTs}}$ will also be discussed.

\section{Results}

1,1,1-Trifluoro-2-phenyl-2-propyl tosylate (3), 2,2,2-trifluoro-1-(4'-methylphenyl)ethyl tosylate (4), 1-tert-bu-

(14) Allen, A. D.; Jansen, M. P.; Koshy, K. M.; Mangru, N. N.; Tidwell, T. T. J. Am. Chem. Soc. 1982, 104, 207.

(15) Liu, K.-T.; Kuo, M.-Y.; Shu, C.-F. Ibid. 1982, 104, 211.

(16) Allen, D. A.; Ambidge, I. C.; Che, C.; Michael, H.; Muir, R. J.; Tidwell, T. T. Ibid. 1983, 105, 2343.

(17) (a) Lin, Y.-S. M.S. Thesis, National Taiwan University, June 1988. (b) A preliminary account of the work on the development of $Y_{\text {BnOT }}$ was presented at the 198th National Meeting of the American Chemical Society, Miami Beach, FL, Sept 10-15, 1989; Abstracts of Papers, ORGN 281.

(18) Winstein, S.; Morse, B. K. J. Am. Chem. Soc. 1952, 74, 1133.

(19) (a) Tsuji, Y.; Fujio, M.; Tsuno, Y. Bull. Chem. Soc. Jpn. 1990, 63, 856. (b) Tsuji, Y.; Yatsugi, K.; Fujio, M.; Tsuno, Y. Mem. Fac. Sci., Kyushu Univ., Ser, C 1990, 17, 281. (c) Tsuji, Y.; Yatsugi, K.; Fujio, M.; Tsuno, Y. Ibid. 1991, 18, 121. (d) Fujio, M.; Tsuji, Y.; Otsu, T.; Tsuno, Y. Tetrahedron Lett. 1991, 32, 1805.

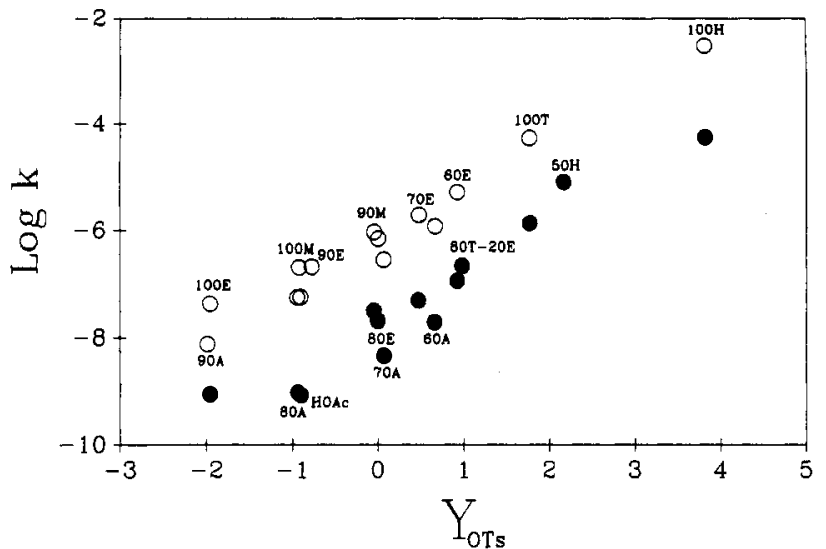

Figure 1. Correlation of logarithms of rate constants for $3(0)$ and $4(0)$ against $Y_{\mathrm{OT}}$.

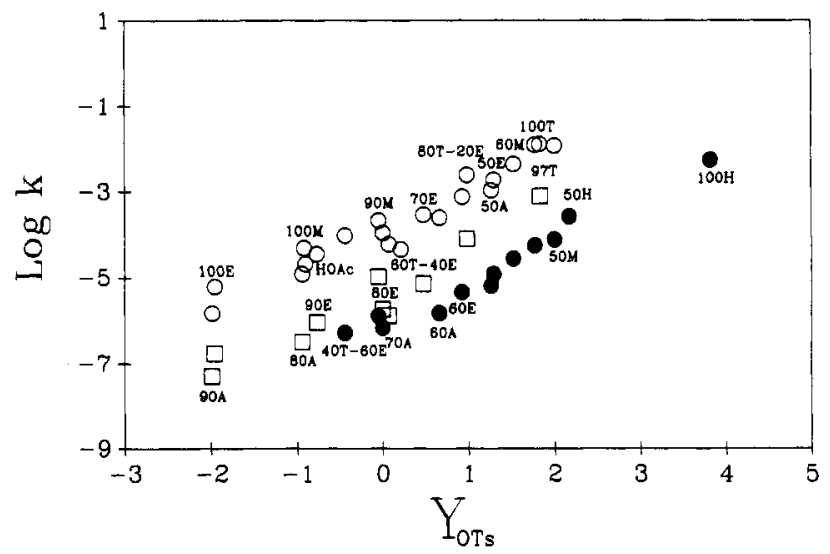

Figure 2. Correlation of logarithms of rate constants for $5(0)$, $6(\bullet)$, and $7(\square)$ against $Y_{O T s}$.

tyl-1-phenylmethyl tosylate (5), 1-tert-butyl-1-(3'-chlorophenyl)methyl tosylate (6), and $1-\left(3^{\prime}, 5^{\prime}\right.$-dichlorophenyl)2,2,2-trifluoro-1-phenylethyl tosylate (7) were prepared from the corresponding alcohols using known procedures. ${ }^{15}$ Spectral data and elemental analyses all agreed with the assigned structures. Solvolytic rate constants for these tosylates in various solvents were measured by the conductimetric method, with the exception of the rates of acetolysis which were monitored titrimetrically. The results are shown in Table I. The solvolysis products were all unarranged. ${ }^{20}$

In most cases, the rate constants for substrates 3-5 in most solvents are in good agreement, generally within $10 \%$, with the literature data. ${ }^{14-16,19}$ However, larger deviation was observed in some occasions for which the $k s$ at $25^{\circ} \mathrm{C}$ were calculated from the data measured at quite high temperature, such as $90^{\circ} \mathrm{C}$ and higher. For example, the extrapolation of the rates of ethanolysis for 4 at $90-130$ ${ }^{\circ} \mathrm{C}$ gave a $k, 8.89 \times 10^{-10} / \mathrm{s}$, and deviated significantly from the reported data, $1.93 \times 10^{-10} / \mathrm{s}^{16}$ For $k(4)$ in $60 \%$ ethanol, which was calculated from the data at 55 and $75^{\circ} \mathrm{C}$, the literature value $\left(1.20 \times 10^{-7} / \mathrm{s}\right)^{16}$ was very close to 1.16 $\times 10^{-7} / 8$ as was found in the present work.

The plots of the logarithm of rate constants, $k(3)$ and $k(4)$, respectively, with $\dot{Y}_{\mathrm{OTa}}^{6,21}$ showed that additional rate constants measured in aqueous acetone and in aqueous

(20) The details on the product study will be reported elsewhere. (21) Although some "corrected" $Y_{\text {OT }}$ values are available (Allard, B.; Casadevall, E. Nouv. J. Chim. 1983, 7, 569), they are limited to ethanol-water and fluorinated alcohol-water mixtures only. In addition, they were derived from the rate data of 2-endo-norbornyl methenesulfonates and might not be appropriate for tosylates. In this study, the revised $Y_{O M}$ values reported in the recent review (ref 6) were employed. 
Table I. Pertinent Solvolytic Rate Constants for Tosylates

\begin{tabular}{|c|c|c|c|c|c|}
\hline \multirow[b]{2}{*}{ solvent ${ }^{a}$} & \multicolumn{5}{|c|}{$k, \mathrm{~s}^{-1}\left(25^{\circ} \mathrm{C}\right)^{b}$} \\
\hline & 3 & 4 & 5 & 6 & 7 \\
\hline $\begin{array}{l}100 \mathrm{E} \\
90 \mathrm{E} \\
80 \mathrm{E} \\
70 \mathrm{E} \\
60 \mathrm{E} \\
50 \mathrm{E} \\
90 \mathrm{~A} \\
80 \mathrm{~A} \\
70 \mathrm{~A} \\
60 \mathrm{~A} \\
50 \mathrm{~A} \\
100 \mathrm{M} \\
90 \mathrm{M} \\
60 \mathrm{M} \\
50 \mathrm{M} \\
100 \mathrm{~T} \\
97 \mathrm{Tw} \\
80 \mathrm{Tw} \\
70 \mathrm{Tw} \\
50 \mathrm{~T} \\
80 \mathrm{~T}-20 \mathrm{E} \\
60 \mathrm{~T}-40 \mathrm{E} \\
40 \mathrm{~T}-60 \mathrm{E} \\
\mathrm{HOAc} \\
100 \mathrm{H} \\
50 \mathrm{H} \\
50 \mathrm{H}-50 \mathrm{~T}\end{array}$ & $\begin{array}{l}4.32 \times 10^{-8 d} \\
2.14 \times 10^{-7} \mathrm{e} \\
7.02 \times 10^{-7 f} \\
1.95 \times 10^{-68} \\
5.24 \times 10^{-68} \\
7.69 \times 10^{-9 h} \\
5.61 \times 10^{-8 i} \\
2.87 \times 10^{-7 j} \\
1.21 \times 10^{-6 k} \\
2.07 \times 10^{-7 l} \\
9.46 \times 10^{-7} \mathrm{~m} \\
\\
5.38 \times 10^{-5}\end{array}$ & $\begin{array}{l}8.89 \times 10^{-100} \\
2.10 \times 10^{-8 p} \\
5.00 \times 10^{-8 q} \\
1.16 \times 10^{-7 r} \\
9.62 \times 10^{-10} \\
4.65 \times 10^{-8 t} \\
1.99 \times 10^{-8 u} \\
3.22 \times 10^{-8 v} \\
1.36 \times 10^{-6 w}\end{array}$ & $\begin{array}{l}6.14 \times 10^{-6 z} \\
3.52 \times 10^{-5} \\
1.07 \times 10^{-4} \\
2.88 \times 10^{-4} \\
7.60 \times 10^{-4} \\
1.87 \times 10^{-3} \\
1.50 \times 10^{-6 a a} \\
1.21 \times 10^{-5} \\
5.90 \times 10^{-5} \\
2.48 \times 10^{-4} \\
1.08 \times 10^{-3} \\
4.87 \times 10^{-5} \\
2.12 \times 10^{-4} \\
4.41 \times 10^{-3} \\
1.17 \times 10^{-2} \\
1.25 \times 10^{-2} \\
1.30 \times 10^{-2} \\
1.44 \times 10^{-2} \\
1.48 \times 10^{-2} \\
1.55 \times 10^{-2} \\
2.48 \times 10^{-3} \\
4.52 \times 10^{-4} \\
9.52 \times 10^{-5} \\
2.07 \times 10^{-5} \\
1.09 b b \\
4.84 \times 10^{-2} b b \\
0.147 b b\end{array}$ & $\begin{array}{l}6.74 \times 10^{-7} \mathrm{cc} \\
4.55 \times 10^{-6 d d} \\
1.18 \times 10^{-5} \\
\\
1.48 \times 10^{-6 e e} \\
6.42 \times 10^{-6} \\
1.28 \times 10^{-6 f f} \\
2.72 \times 10^{-5} \\
7.62 \times 10^{-5} \\
5.57 \times 10^{-5}\end{array}$ & $\begin{array}{l}1.72 \times 10^{-7 h h} \\
9.06 \times 10^{-7 i i} \\
1.84 \times 10^{-6 j j} \\
7.21 \times 10^{-6} \\
\\
5.04 \times 10^{-8 \mathrm{kk}} \\
3.18 \times 10^{-7 u} \\
1.32 \times 10^{-8 \mathrm{~mm}}\end{array}$ \\
\hline
\end{tabular}

${ }^{a}$ For abbreviation of solvents: A, acetone; E, ethanol; M, methanol; H, hexafluoro-2-propanol; T, 2,2,2-trifluoroethanol. The numbers denote the volume percent of the specific solvent in the solvent mixture, unless otherwise mentioned. The amount of water is not recorded. ${ }^{b}$ Obtained in this work unless otherwise mentioned. ' Weight percent. ${ }^{d}$ Reference 6 . $\mathrm{e}-\mathrm{f}$ Calculated from data at other temperature, $k, \mathrm{~s}^{-1}$ $\left({ }^{\circ} \mathrm{C}\right)$ : $(e) 9.73 \times 10^{-6}(75.0), 1.88 \times 10^{-5}(60.0) ;(f) 3.47 \times 10^{-4}(75.0), 5.82 \times 10^{-5}(60.0) ; 2.05 \times 10^{-5}(50.0)$. B Reference 15 . ho Calculated from data at other temperature, $k, \mathrm{~s}^{-1}\left({ }^{\circ} \mathrm{C}\right)$ : (h) $7.79 \times 10^{-4}(125.0), 7.79 \times 10^{-5}(100.0)$; (i) $1.54 \times 10^{-4}(90.0), 4.24 \times 10^{-6}(75.0), 9.86 \times 10^{-6}(65.0)$; (j) $1.58 \times 10^{-4}(75.0), 2.90 \times 10^{-5}$; (k) $3.64 \times 10^{-4}(70.0), 1.01 \times 10^{-4}(60.0), 3.58 \times 10^{-5}(50.0) ;(\mathrm{l}) 1.29 \times 10^{-4}(75.0), 2.29 \times 10^{-6}(60.0)$; (m) 4.19 $\times 10^{-4}(75.0), 8.16 \times 10^{-5}(60.0) ;(\mathrm{n}) 5.18 \times 10^{-4}(100.0), 1.63 \times 10^{-4}(90.0), 3.83 \times 10^{-5}(75.0) ;(0) 8.78 \times 10^{-5}(130), 2.28 \times 10^{-5}(113.6), 1.05 \times$ $10^{-6}(105.0), 2.40 \times 10^{-6}(90.0)$. ${ }^{p}$ Reference 16. ${ }^{q-a}$ Calculated from date at other temperature, $k, s^{-1}\left({ }^{\circ} \mathrm{C}\right):(q) 1.08 \times 10^{-4}(105.0), 2.20 \times 10^{-5}$ $(90.0), 4.30 \times 10^{-6}(75.0) ;(\mathrm{r}) 5.93 \times 10^{-6}(75.0), 6.15 \times 10^{-6}(55.0) ;(8) 6.44 \times 10^{-5}(115.0), 2.52 \times 10^{-5}(105.0), 5.12 \times 10^{-8}(90.0) ;(\mathrm{t}) 1.08 \times 10^{-4}$ (105.0), $2.20 \times 10^{-5}(90.0), 4.30 \times 10^{-6}(75.0)$; (u) $5.37 \times 10^{-4}(110.0), 1.91 \times 10^{-4}(100.0), 4.40 \times 10^{-5}$ (85.0); (v) $1.49 \times 10^{-4}(100.0), 3.41 \times 10^{-6}$ $(85.0), 1.37 \times 10^{-5}(75.0) ;(\mathrm{w}) 1.64 \times 10^{-4}(75.0), 4.52 \times 10^{-5}(60.0) ;(\mathrm{x}) 1.09 \times 10^{-4}(85.0), 4.48 \times 10^{-5}(75.0), 1.75 \times 10^{-5}(65.0) ;(\mathrm{y}) 1.99 \times 10^{-4}$ $(130.0) ; 1.94 \times 10^{-5}(105.0) ;(\mathrm{z}) 9.43 \times 10^{-4}(65.0), 4.71 \times 10^{-6}(40.0) ;(\mathrm{aa}) 6.00 \times 10^{-4}(75.0), 3.78 \times 10^{-6}$ (50.0). bb Extrapolated from linear plots with $\log k(6)$. ${ }^{c c-m m}$ Calculated from data at other temperature, $k, \mathrm{~s}^{-1}\left({ }^{\circ} \mathrm{C}\right)$ : (cc) $3.35 \times 10^{-4}(75.0), 1.91 \times 10^{-5}(50.0) ;(\mathrm{dd}) 6.67 \times 10^{-4}$

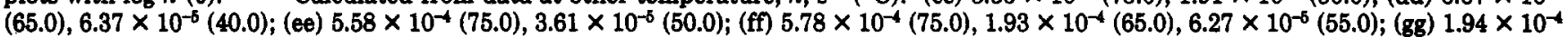
(75.0), $2.26 \times 10^{-5}(50.0)$; (hh) $8.20 \times 10^{-5}(75.0), 4.77 \times 10^{-6}(50.0)$; (ii) $3.92 \times 10^{-4}(75.0), 7.49 \times 10^{-5}(60.0), 2.40 \times 10^{-5}(50.0) ;(\mathrm{ji}) 2.48 \times 10^{-4}$ $(60.0), 6.80 \times 10^{-5}(50.0) ;(\mathrm{kk}) 2.48 \times 10^{-4}(100.0), 6.80 \times 10^{-5}(75.0) ;(11) 1.72 \times 10^{-4}(75.0), 3.18 \times 10^{-6}(60.0) ;(\mathrm{mm}) 6.46 \times 10^{-4}(60.0), 5.92 \times$ $10^{-6}(40.0)$.

Table II. Correlation Analyses of Rate Data against $\boldsymbol{Y}_{\text {OT: }}$

\begin{tabular}{ccccc}
\hline substrate & $n^{a}$ & $m$ & $R$ & SD \\
\hline $\mathbf{3}$ & 14 & 0.911 & 0.979 & 0.054 \\
$\mathbf{4}$ & 13 & 0.976 & 0.964 & 0.081 \\
$\mathbf{5}$ & 21 & 0.964 & 0.976 & 0.049 \\
$\mathbf{6}$ & 12 & 1.000 & 0.981 & 0.062 \\
7 & 10 & 0.992 & 0.953 & 0.112
\end{tabular}

- Number of solvents.

Table III. Correlation Analyees of Rate Data against $Y_{\text {OT: }}$ and $N(O T s)$

\begin{tabular}{crccc}
\hline substrate & $n^{\alpha}$ & $m$ & $l$ & $R$ \\
\hline 3 & 10 & 0.863 & -0.247 & 0.983 \\
4 & 8 & 0.672 & -0.217 & 0.990 \\
5 & 12 & 0.837 & -0.130 & 0.989 \\
6 & 6 & 0.963 & -0.081 & 0.996 \\
7 & 5 & 0.616 & -0.482 & 0.997
\end{tabular}

a Number of solvents whose $N(\mathrm{OT})$ values are available.

methanol deviated from the original linear relationships ${ }^{14-16}$ (Figure 1). Similar deviations were also observed in the solvolysis of secondary tosylates 5 and 6 and the tertiary tosylate 7 as well (Figure 2). The results of correlation analyses using eqs 1 and 2 are summarized in Tables II and III, respectively.

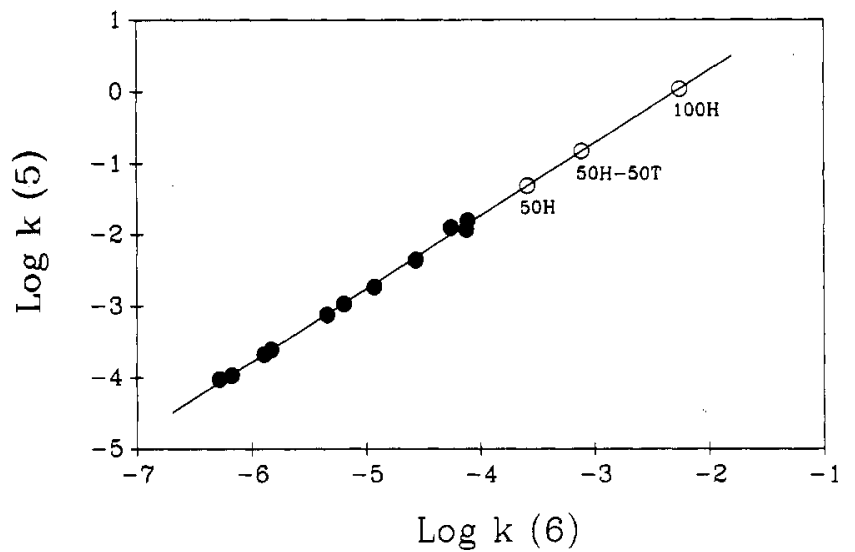

Figure 3. Correlation of logarithms of rate constants for $5(\theta)$ against that for 6 .

However, an excellent linear relationship between log $k(5)$ and $\log k(6), m=1.019$ and $R=0.998$, was observed. Therefore, some very fast rate constants for 5 could be calculated by extrapolation (Figure 3, open circle). Moreover, excellent linear correlations were also found if $\log k s$ for 5 were plotted against $\log k s$ for 3,4 , and 7 , respectively. A new $Y_{\mathrm{BnOT}}$ scale of solvent ionizing powers based on the logarithms of the $k s$ for 5 can thus be de- 


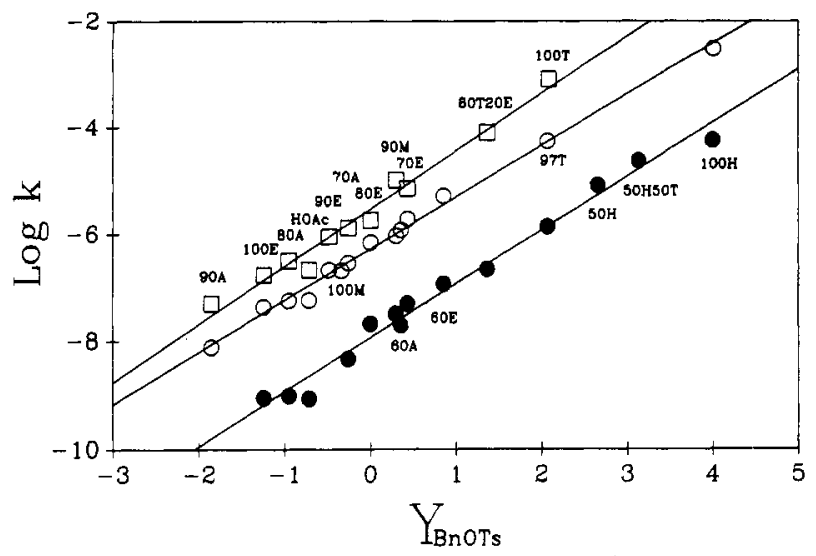

Figure 4. Correlation of logarithms of rate constants for $3(0)$, $4(\Theta)$, and7 (a) against $Y_{\mathrm{BnOT}}$.

Table IV. Comparison of $Y$ Scales

\begin{tabular}{lcr}
\hline solvent & $Y_{\text {BnOT: }}$ & $Y_{\mathrm{OTs}^{a}}{ }^{a}$ \\
\hline $100 \mathrm{E}$ & -1.24 & -1.96 \\
$90 \mathrm{E}$ & -0.483 & -0.77 \\
$80 \mathrm{E}$ & 0.000 & 0.00 \\
$70 \mathrm{E}$ & 0.430 & 0.47 \\
$60 \mathrm{E}$ & 0.851 & 0.92 \\
$50 \mathrm{E}$ & 1.24 & 1.29 \\
$90 \mathrm{~A}$ & -1.85 & -1.99 \\
$80 \mathrm{~A}$ & -0.947 & -0.94 \\
$70 \mathrm{~A}$ & -0.259 & 0.07 \\
$60 \mathrm{~A}$ & 0.354 & 0.66 \\
$50 \mathrm{~A}$ & 1.00 & 1.26 \\
$100 \mathrm{M}$ & -0.342 & -0.92 \\
$90 \mathrm{M}$ & 0.297 & -0.05 \\
$60 \mathrm{M}$ & 1.62 & 1.52 \\
$50 \mathrm{M}$ & 2.04 & 2.00 \\
HOAc & -0.713 & -0.90 \\
$100 \mathrm{~T}$ & 2.07 & 1.77 \\
$97 \mathrm{Tw}$ & 2.09 & 1.83 \\
$80 \mathrm{Tw}$ & 2.13 & \\
$70 \mathrm{Tw}$ & 2.14 & 2.00 \\
$50 \mathrm{~T}$ & 2.16 & \\
$80 \mathrm{~T}-20 \mathrm{E}$ & 1.37 & 0.98 \\
$60 \mathrm{~T}-40 \mathrm{E}$ & 0.626 & 0.21 \\
$40 \mathrm{~T}-60 \mathrm{E}$ & -0.051 & -0.44 \\
$100 \mathrm{H}$ & 4.01 & 3.82 \\
$50 \mathrm{H}$ & 2.66 & $2.17^{b}$ \\
$50 \mathrm{H}-50 \mathrm{~T}$ & 3.14 &
\end{tabular}

a Reference 2b. ' Allard, B.; Casadevall, E. Nouv. J. Chem. 1983, 7,569 .

Table V. Correlation Analyses of Rate Data against $\boldsymbol{Y}_{\text {BuOT: }}$

\begin{tabular}{cllll}
\hline substrate & $n^{a}$ & \multicolumn{1}{c}{$m$} & \multicolumn{1}{c}{$R$} & SD \\
\hline 3 & 14 & 0.964 & 0.996 & 0.024 \\
4 & 14 & 0.999 & 0.992 & 0.038 \\
6 & 14 & 0.979 & 0.999 & 0.010 \\
7 & 10 & 1.06 & 0.994 & 0.043
\end{tabular}

a Number of solvents.

veloped. The values are shown in Table IV, and the results of correlation analyses by using these new $Y_{8}$ are listed in Table V.

\section{Discussion}

It has been shown that solvent nucleophilicity plays an important role in the solvolysis of primary benzyl tosylates ${ }^{22}$ and secondary deactivated 1-arylethyl tosylates. ${ }^{23}$ For tosylates 3-7, although a small deceleration of the rates

(22) Kevill, D. N.; Ren, H. J. Org. Chem. 1989, 54, 5654.

(23) Allen, A. D.; Kanagasabathy, V. M.; Tidwell, T. T. J. Am. Chem. Soc. 1985, 107, 4513 . in acetic acid was realized, no significant deviation was observed for those in hexafluoro-2-propanol or trifluoroethanol (Figures 1 and 2). The nonlinear relationships could be improved from $R=0.95-0.98$ by using eq 1 (Table II) to $R=0.98-0.99$ (Table III) if the multiparameter eq 2 was employed. However, this improvement cannot be interpretated by an intervention of solvent nucleophilicity because in the cases of 3 and 7 the overcrowded tertiary reaction center in the solvolytic transition state excludes the possibility of solvent participation. Moreover, the limiting $S_{N} 1$ mechanism has been demonstrated for the solvolysis of secondary substrates $4,16,24,255$, and $6 .^{19}$ Therefore, it is likely that the $Y_{\mathrm{OTB}}$ scale might not be a proper one for benzylic tosylates.

The deviation from linear Grunwald-Winstein plots against $Y_{X}$ (eq 1) observed in the present study is very similar to that has been shown in our previous work. ${ }^{11-13}$ For instance, individual linear relationships could be found for the data in aqueous acetone, aqueous ethanol, aqueous methanol, and ethanol-trifluoroethanol, respectively. The data points for those measured in aqueous acetone always showed depression from the line defined by those measured in aqueous ethanol or methanol. Thus, the scattered plots did not result from random errors. Moreover, the order of reactivities such as $k(100 \mathrm{M})>k(90 \mathrm{E})>k(80 \mathrm{~A})$ could not be accomodated by Swain's parameter $B,{ }^{26}$ which denotes the solvation ability of localized cations. Another possible explanation by the intervention of ion pair return would be unlikely, since no dependence of deviation on reactivities (Table I) ${ }^{27}$ or on the amount of return ${ }^{19 c}$ could be observed. Consequently, it is likely that the $Y_{\text {otr }}$ scale is not appropriate to apply to systems with delocalized cationic transition states as that for bromides, chlorides, and $p$-nitrobenzoates, which have been found in the previous studies. ${ }^{11-13}$

Since the tertiary tosylate 1d would be very unstable and very reactive, other reference substrates should be chosen. Evidence for the absence of nucleophilic solvent assistance or methyl participation in the solvolysis of 1-aryl-1-tertbutylmethyl tosylates has already been shown. ${ }^{19}$ The lack of solvent intervention in the solvolysis of the sterically hindered tosylate $5^{18}$ can be further proved by additional evidence. The relative rate ratios of $141-256$ for tosylate/bromide in aqueous ethanol ${ }^{28}$ are in line with the value of 231 observed for the 2-adamantyl system. ${ }^{20}$ In addition, the $\alpha$-deuterium kinetic isotope effect, $1.19-1.21$ in aqueous ethanol, ${ }^{30}$ also agrees with that predicted for $\mathrm{S}_{\mathrm{N}} 1$ process. ${ }^{31}$ A new $Y$ scale based on the rates of solvolysis of 5 is thus a reasonable choice. Accordingly, a $Y_{\mathrm{BnOTn}}$ scale could be developed on the basis of eq 1 for correlating the solvolytic reactivities of benzylic tosylates by using 5 as the reference standard and 6 for extrapolation.

The comparison of $Y_{\mathrm{BnOTs}}$ with $Y_{\mathrm{OTs}}{ }^{6}$ (Table IV) reveals that the latter is always more negative except in acetone-water and in ethanol-water. In those solvents the $Y_{\text {OT }}$ may be more negative than the new $Y_{\mathrm{BnOT}}$ at lower

(24) Richard, J. P. J. Am. Chem. Soc. 1989, 111, 1455.

(25) Murata, A.; Sakagachi, S.; Fujiyama, R.; Mishima, M.; Fujio, M.; Tsuno, Y. Bull. Chem. Soc. Jpn. 1990, 63, 1138.

(26) Swain, C. G.; Swain, M. S.; Powell, A. L.; Alumni, S. J. Am. Chem. Soc. $1983,105,502$.

(27) Similar results were also found in the solvolysis of substituted naphthylmethyl tosylates. See: Liu, K.-T.; Hsu, H.-Y.; Yang, J.-S. Tetrahedron Lett., in press.

(28) Yang, J.-S. M.S. Thesis, National Taiwan University, June 1990 (29) Bingham, R. C.; Schleyer, P. v. R. J. Am. Chem. Soc. 1971, 93, 3189.

(30) Sheu, H.-C. Ph.D. Thesis, National Taiwan University, July 1991.

(31) Melander, L. Saunders, W. H. Jr. Reaction Rates of Isotopic Molecules; Wiley-Interscience: New York, 1980; Chapter 6. 
Table VI. Comparison of Correlation Analyses of Some Tosylates Using eq 2

\begin{tabular}{|c|c|c|c|c|c|c|c|c|c|}
\hline \multirow[b]{2}{*}{ substrate } & \multirow[b]{2}{*}{$Y$} & \multicolumn{4}{|c|}{$N(\mathrm{OTs})$} & \multicolumn{4}{|c|}{$N(\mathrm{~T})$} \\
\hline & & $n^{a}$ & $l$ & $m$ & $R$ & $\overline{n^{a}}$ & $l$ & $m$ & $R$ \\
\hline \multirow[t]{2}{*}{8} & $Y_{\text {OTs }^{b}}^{b}$ & 7 & $\begin{array}{c}0.488 \\
(0.104)^{e}\end{array}$ & $\begin{array}{c}0.568 \\
(0.087)\end{array}$ & 0.959 & 6 & $\begin{array}{c}0.510 \\
(0.163)\end{array}$ & $\begin{array}{c}0.712 \\
(0.170)\end{array}$ & 0.925 \\
\hline & $Y_{\mathrm{BnOTs}}{ }^{c}$ & 7 & $\begin{array}{c}0.520 \\
(0.046)\end{array}$ & $\begin{array}{c}0.668 \\
(0.043)\end{array}$ & 0.992 & 6 & $\begin{array}{c}0.585 \\
(0.066)\end{array}$ & $\begin{array}{c}0.913 \\
(0.079)\end{array}$ & 0.989 \\
\hline \multirow[t]{2}{*}{9} & $Y_{\mathrm{OTs}^{d}}{ }^{d}$ & 8 & $\begin{array}{c}0.198 \\
(0.063)\end{array}$ & $\begin{array}{c}0.759 \\
(0.059)\end{array}$ & 0.991 & 7 & $\begin{array}{c}0.180 \\
(0.091)\end{array}$ & $\begin{array}{c}0.798 \\
(0.102)\end{array}$ & 0.986 \\
\hline & $Y_{\mathrm{BnOTs}}{ }^{c}$ & 8 & $\begin{array}{c}0.272 \\
(0.031)\end{array}$ & $\begin{array}{c}0.856 \\
(0.031)\end{array}$ & 0.998 & 7 & $\begin{array}{c}0.285 \\
(0.059)\end{array}$ & $\begin{array}{c}0.951 \\
(0.070)\end{array}$ & 0.995 \\
\hline \multirow[t]{2}{*}{10} & $Y_{\mathrm{OTH}^{d}}{ }^{d}$ & 7 & $\begin{array}{c}0.317 \\
(0.075)\end{array}$ & $\begin{array}{c}0.699 \\
(0.066)\end{array}$ & 0.989 & 6 & $\begin{array}{c}0.297 \\
(0.143)\end{array}$ & $\begin{array}{c}0.769 \\
(0.151)\end{array}$ & 0.978 \\
\hline & $Y_{\mathrm{BDOT} \mathrm{s}^{c}}$ & 7 & $\begin{array}{c}0.347 \\
(0.045)\end{array}$ & $\begin{array}{c}0.757 \\
(0.041)\end{array}$ & 0.997 & 6 & $\begin{array}{c}0.357 \\
(0.104)\end{array}$ & $\begin{array}{c}0.873 \\
(0.116)\end{array}$ & 0.989 \\
\hline
\end{tabular}

${ }^{a}$ Number of solvents whose $N$ values are available. ${ }^{b}$ Recalculation of the literature data (ref 34 ) using $Y_{\text {OTs }}$ (ref 6 ). ${ }^{c}$ Recalculation of the literature data (ref 34) using $Y_{\mathrm{BnOTs}}$. ${ }^{d}$ Recalculation of the literature data (ref 23) using $Y_{\mathrm{OTs}}$ (ref 6). ${ }^{e}$ Standard deviation.

water content $(100 \mathrm{E}, 90 \mathrm{E}, 90 \mathrm{~A}$, and $80 \mathrm{~A})$, or more positive at higher water content (70E-50E and $70 \mathrm{~A}-50 \mathrm{~A})$. It seems plausible that the delocalized benzylic cationic transition state will be relatively less favored than the localized 1adamantyl cation in solvents of higher solvation energy, as has been realized in previous work. ${ }^{11-13,32}$ Furthermore, both the electrophilicity and the nucleophilicity of the solvents ${ }^{33}$ are likely to be important as in the cases of bromides $^{12}$ and chlorides. ${ }^{11 \mathrm{~b}}$

The advantages of employing this new $Y$ scale can be illustrated by the excellent correlation for $3,4,6$, and 7 ion Table V $(R>0.99)$ as compared with the less satisfactory results in Table II $(R=0.95-0.98)$. The scattered $\log k-Y_{0 T}$ plots in the cases of $3(R=0.979)$ and $7(R$ $=0.953$ ) (Figure 1) are likely the outcome of using of an improper $Y$ scale. Since both tosylates are highly hindered and are not susceptible to nucleophilic solvent participation, the observed good linear correlation for these substrates (Table III) with the multiparameter eq 2 (vide supra) could therefore be considered as artifacts. In the solvolytic study of benzyl tosylate (8), Kevill and coworkers ${ }^{34}$ suggested the use of $Y_{\mathrm{OTs}}$ and $N\left(\mathrm{Et}_{3} \mathrm{O}^{+}\right)^{35}$ in eq 2. Other $N$ scales, $N(\mathrm{~T})$ and $N^{\prime}(\mathrm{OTs})$, were also developed recently. ${ }^{36}$ Recalculation using the new $Y_{\mathrm{BnOTs}}$ values, as compared $Y_{\mathrm{OTs}}$, indicated the combination of $Y_{\mathrm{BnOTs}}$ and $N(\mathrm{OTs})^{37}(R=0.992)$ or $N^{\prime}(\mathrm{OTs})(R=0.997)$ would be better than the use of other values $(R=0.925-0.989)$ in the correlation analyses. In other words, $N(\mathrm{OTs})$ or $N^{\prime}$. (OTs) seems to be the choice for neutral substrates. In the cases of $1-\left(3^{\prime}\right.$-bromophenyl)ethyl $(9)$ and $1-\left[3^{\prime}\right.$-(trifluoromethyl)phenyl]ethyl tosylates (10), Tidwell and coworkers $^{23}$ have found linear relationships by using $Y_{O T s}$ and $N(\mathrm{OTs})$ in eq 2 for correlation analyses. Owing to the fact that only 4-6 $N^{\prime}(\mathrm{OTs})$ or $N\left(\mathrm{Et}_{3} \mathrm{O}^{+}\right)$values are available for substrates 9 and 10 , the results of regression analyses using these values are not given in Table VI for comparison. Better linear relationships for $9(R=0.998)$ and $10(R=$ 0.997 ) could be obtained if $Y_{\mathrm{BnOTB}}$ and $N(\mathrm{OTs})$ were used for calculation. ${ }^{38}$ The standard deviations for $l$ and $m$ were 1604.

(32) Bentley, T. W.; Koo, 1. S.; Norman, S. J. J. Org. Chem. 1991, 56

(33) Abraham, M. H.; Doherty, R. M.; Kalmet, M. J.; Harris, J. M.; Taft, R. W. J. Chem. Soc., Perkin Trans. 2 1987, 913

(34) Kevill, D. N.; Rissmann, T. J. J. Chem. Res., Synop. 1986, 252.

(35) Kevill, D. N.; Anderson, S. W.; Fujimoto, E. K. In Nucleophilicity; Harris, J. M., McManus, S. P., Ed.; Advances in Chemistry 215; American Chemical Society: Washington DC, 1987; pp 269-283.

(36) Kevill, D. N.; Anderson, S. W. J. Org. Chem. 1991, 56, 1845.

(37) Schadt, F. L.; Bentley, T. W.; Schleyer, P. v. R. J. Am. Chem. Soc. 1976, 98, 7667 . also smaller, so the superiority of using $Y_{\mathrm{BnOTB}}$ was obvious. The importance of solvent nucleophilicity in the solvolysis of 9 and $10^{23}$ could thus be confirmed.

Consequently, the $Y_{\mathrm{OTs}}$ scale will not be as good as the new $Y_{\mathrm{BnOTs}}$ scale in correlating reactivities and in examining the nucleophilic solvent effect in the solvolysis of benzylic tosylates, in which delocalized cationic transition states were formed. The importance of the solvation on the cationic moiety in the transition state can also be demonstrated in the solvolysis of substituted naphthylmethyl tosylates. ${ }^{27}$ More work on the solvolysis of other tosylates is in progress.

\section{Experimental Section}

General Remarks. Capillary melting points were uncorrected. NMR spectra were determined on a Varian EM390 instrument using tetramethylsilane as internal standard. IR spectra were measured on a Perkin-Elmer Model 983G spectrometer. Mass spectral analyses were obtained with a Finigan TSQ-16C instrument. Elemental analyses were done in the Microanalytical Laboratory of this department.

Materials. Solvents for the kinetic studies were spectral grade or reagent grade and purified according to standard procedures. ${ }^{3 \theta}$ Dry solvents were freshly distilled before use.

The tosylates 3-7 were prepared according to literature procedures. ${ }^{7}$ The spectral data are in harmony with the assigned structures, and the melting points for 3-6 agree with the reported values: $3, \mathrm{mp} 103.5^{\circ} \mathrm{C} ; 7^{7} 4,82-83^{\circ} \mathrm{C}$ (lit. ${ }^{8} \mathrm{mp} 81.5-82{ }^{\circ} \mathrm{C}$; lit. ${ }^{14}$ $\mathrm{mp} 85.5-85.8{ }^{\circ} \mathrm{C}$ ); 5, 67-68 ${ }^{\circ} \mathrm{C}$ (lit. ${ }^{9} \mathrm{mp} 68.2-68.9^{\circ} \mathrm{C}$ ); 6, 83-84 ${ }^{\circ} \mathrm{C} 9$. The mp and pertinent spectral data for 7 are listed as follows: $\mathrm{mp} 117-118^{\circ} \mathrm{C} ;{ }^{1} \mathrm{H}$ NMR, $\delta\left(\mathrm{CDCl}_{3}\right) 2.28\left(\mathrm{~s}, 3 \mathrm{H}, \mathrm{CH}_{3}\right), 7.03-7.33$ $\left(\mathrm{m}, 12 \mathrm{H}\right.$, aromatic protons); IR $\nu_{\max }(\mathrm{KBr}) 1370,1180(\mathrm{~s}, \mathrm{~S}=0)$ $\mathrm{cm}^{-1} ; \mathrm{MS} \mathrm{m} / z(12 \mathrm{eV}) 303\left(100, \mathrm{M}-\mathrm{OTs}^{+}\right), 305\left(65, \mathrm{M}+2^{\circ+}\right.$ OTs), $474\left(17, \mathrm{M}^{*+}\right), 476\left(11, \mathrm{M}+2^{*+}\right)$. Anal. Calcd for $\mathrm{C}_{20} \mathrm{H}_{15} \mathrm{O}_{3} \mathrm{~F}_{3} \mathrm{Cl}_{2}$ : C, 53.06; $\mathrm{H}, 3.18$. Found, $\mathrm{C}, 53.26 ; \mathrm{H}, 3.18$.

Kinetic Measurements. Conductimetric rate constants were measured, with the exception of acetolysis, using an automatically PC-AT or XT monitored multichannel system developed in this laboratory. The conductivity cells were placed in the thermostat with temperature variation of $\pm 0.02^{\circ} \mathrm{C}$. Solutions of $10^{-4}-10^{-5}$ $\mathrm{M}$ were employed in this study. In some cases, the addition of a small amount of 2,6-lutidine to the solution was found to be necessary to prevent curvature of the rate constant plot. A titrametrical method was employed with a solution of $0.005-0.01$ $\mathrm{M}$ for the study of acetolysis. ${ }^{40}$

All reactions were followed to 10 or more half-lives and showed excellent first-order behavior. Arrhenius plots of rate data obtained at other temperature were used to estimate rate constants

(38) $R=0.978-0.995$ if $N\left(\mathrm{Et}_{3} \mathrm{O}^{+}\right)$was used, and $R=0.989-0.996$ if $N^{\prime}(\mathrm{OTs})$ was used.

(39) Perrin, D. D.; Armarego, W. L. F. Purification of Laboratory Chemicals, 3rd ed.; Pergamon Press: New York, 1988.

(40) Fainberg, A. H.; Winstein, S. J. Am. Chem. Soc. 1956, 78, 2770. 
at $25^{\circ} \mathrm{C}$ which could not be measured directly. Each rate constant was determined at least in duplicate, and the deviation was smaller than $\pm 3 \%$. The mean values of these data are listed in Table I.

Acknowledgment. The authors are grateful to the
National Science Council for financial support of this research.

Registry No. $3,73572-26-6 ; 4,84877-44-1 ; 5,91787-10-9 ; 6$, $120136-10-9 ; 7,96236-00-9 ; 8,1024-41-5 ; 9,139760-46-6 ; 10$, 139760-47-7.

\title{
Synthesis of New Amphiphilic Perfluoroalkylated Bipyridines
}

\author{
Nathalie Garelli and Pierre Vierling* \\ Laboratoire de Chimie Moléculaire, Unitê de Recherche Associēe au C.N.R.S., Universitê de Nice-Sophia \\ Antipolis, 06108 Nice Cedex 2, France
}

Received November 5, 1991

\begin{abstract}
General and versatile synthetic methods have been developed for the preparation of a large variety of $2,2^{\prime}$ bipyridines bearing two various perfluoroalkylated side chains with an ester or a methylene junction in the

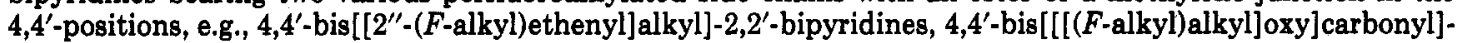
$2,2^{\prime}$-bipyridines, and $4,4^{\prime}$-bis[[[[2'-(F-alkyl)ethenyl]alkyl $]$ oxy $]$ carbonyl]-2,2'-bipyridines.
\end{abstract}

\section{Introduction}

An area of growing interest lies in the use of ligands and their transition-metal complexes exhibiting amphiphilic properties capable of being inserted into interfacial films, membranes, liposomes, and other organized supramolecular systems. A more important objective is to develop novel chemistry based on membrane-mediated processes in relatively simple systems. Such organized systems have been utilized in reactivity control, photochemical solar energy conversion and storage, transport, and drug encapsulation and providing unique environments for substrates and enzymes. ${ }^{1}$

Our goal is to develop metal complexes which may be transported by vesicles (or liposomes) or by injectable fluorocarbon emulsions to be used simultaneously as drug delivery systems and as artificial oxygen carriers. In order to achieve this goal, it was necessary to synthesize new highly amphiphilic ligands bearing, in particular, perfluoroalkylated side chains. Such derivatives may find several potential applications, namely in therapy for the transport and targeting of drugs based on transition-metal complexes and in the constitution of functionalized dispersed systems which may operate as catalytic microreactors.

We describe here the preparation of a new class of amphiphilic ligands in which the coordinating head consists of a bipyridine moiety and the hydrophobic part of two hydrocarbon chains of various lengths terminated by highly perfluoroalkylated tails.

The presence of the bipyridine head on these new compounds opens up a large field of applications. Very few organic ligands have received more attention than $2,2^{\prime}$ bipyridine and its analogues. Bipyridine ligands are widely used in coordination chemistry and catalysis. ${ }^{2}$ The interest in such ligands stems, in particular, from their exceptional photoredox properties and from the peculiar photochemical and photophysical properties exhibited by several of their transition-metal complexes. ${ }^{3}$ Elaborate

(1) Fendler, J. H. In Membrane Mimetic Chemistry; John Wiley \& Sons: New York, 1982.

(2) Zeissel, R. Nouveau J. Chim. 1983, 7, 613.

(3) Juris, A.; Barigelletti, F.; Campagna, S.; Balzani, V.; Belser, P.; von Zelensky, A. Coord. Chem. Reu. 1988, 84, 85. systems exploiting such properties have indeed emerged, especially in redox electrocatalysis ${ }^{4}$ and light-induced electron-transfer reactions that convert solar energy into chemical energy. ${ }^{5}$ Furthermore, several $2,2^{\prime}$-bipyridinemetal complexes were found to be endowed with antimicrobial, ${ }^{6}$ antifungal, ${ }^{7}$ and antineoplasmic ${ }^{8}$ activity.

The perfluoroalkylated tails are intended to increase the hydrophobic and fluorophilic character of these amphiphilic ligands, hence of their transition-metal complexes, to facilitate, respectively, their incorporation into liposomes and into oxygen-delivering fluorocarbon emulsions. The encapsulation into liposomes of a drug usually improves its therapeutic index, hence its efficiency, by reducing its toxicity, prolonging its intravascular persistence, and modifying its biodistribution. ${ }^{9}$ Furthermore, the incorporation of a drug in fluorocarbon emulsions is expected to combine the numerous advantages of drug encapsulation with the capacity of the fluorocarbon to deliver oxygen in radio- $^{-10}$ and chemoresistant ${ }^{11}$ tumors, thus enhancing the tumoricidal effects of radiations or of cytotoxic drugs. Such a synergistic effect has been shown in the treatment of tumors with alkylating agents, antimetabolites, and antibiotics used in conjunction with fluorocarbon emulsions. ${ }^{12}$ In addition, the use of fluorocarbon emulsions in therapy as drug delivery systems is particularly attractive in view of their high intravascular persistence and

(4) Collin, J. P.; Sauvage, J. P. Coord. Chem. Rev. 1989, 93, 254.

(5) (a) Grätzel, M.; Kalyanasundaram, K.; Kiwi, J. Struct. Bonding (Berlin) 1982, 49, 37. (b) Lehn, J. M. Actual. Chim. 1982, 12, 13.

(6) Craciunescu, D.; Scarcia, V.; Furlani, A.; Gbirvu, C.; Ravalico, L.; Doadrio, A. Acta Pharm. Fennica 1987, 96, 157.

(7) Cristalli, G.; Franchetti, P.; Nasini, E.; Vittori, S.; Grifantini, M.; Barzi, A.; Lepri, E.; Ripa, S. Eur. J. Med. Chem. 1988, 23, 301.

(8) Gill, D. S. In Platinum Coordination Complexes in Cancer Chemotherapy; Hacker, M. P., Douple, D. P., Krakoff, H. I., Eds.; Martinus Nishoff: Boston, 1984; p 290.

(9) (a) Lopez-Berestein, G.; Fidler, I. J. Liposomes in the Therapy of Infectious Diseases and Cancer; A. R. Liss: New York, 1989. (b) Mayew, E.; Papahadjopoulos, D. In Liposomes; Ostro, M. J., Ed.; M. Dekker: New York, 1983; p 289. (c) Gregoriadis, G. Liposomes as Drug Carriers; John Wiley \& Sons: New York, 1988.

(10) (a) Rockwell, S. Int. J. Radiat. Oncol. Biol. Phys. 1985, 11, 97. (b) Thomas, C.; Riess, J. G.; Guichard, M. Int. J. Radiat. Biol. 1991, 59, 433 , (11) Teicher, B. A.; Herman, T. S.; Tanaka, J.; Eder, J. P.; Holden, S. A.; Bubley, G.; Coleman, C. N.; Frei, E., III. Cancer Res. 1991, 51, 1086. (12) Teicher, B. A.; Mcintosh-Lowe, N. L.; Rose, C. M. In Biomat., Art. Cells, Art. Org.; Chang, T. M. S., Geyer, R., Eds.; M. Dekker: New York, 1988; Vol. 16, p 533. 